\title{
Association Between Plasma Lipids Profile and Lipids Oxidizability in Healthy Men
}

\author{
Ameneh Jafari ${ }^{1{ }^{2 *}}$, Bemanali Jalali Khanabadi ${ }^{3}$, Naser Nejadi ${ }^{4}$, Behrouz Farhadihosseinabadi1,5 \\ ${ }^{1}$ Student Research Committee, School of Medicine, Shahid Beheshti University of Medical Sciences, Tehran, Iran \\ ${ }^{2}$ Proteomics Research Center, School of Allied Medicine, Shahid Beheshti University of Medical Sciences, Tehran, Iran \\ ${ }^{3}$ Department of Biochemistry, Shahid Sadoughi University of Medical Sciences, Yazd, Iran \\ ${ }^{4}$ Department of Clinical Biochemistry, Faculty of Medical Sciences, Tarbiat Modares University, Tehran, Iran \\ ${ }^{5}$ Department of Biotechnology, School of Advanced Technologies in Medicine, Shahid Beheshti University of Medical Sciences, \\ Tehran, Iran
}

Corresponding Author: Ameneh Jafari, PhD, Proteomics Research Center, School of Allied Medicine, Shahid Beheshti University of Medical Sciences, Tehran, Iran. Email: Amenehjafari@gmail.com

Received January 3, 2019; Accepted April 22, 2019; Online Published June 24, 2019

\begin{abstract}
Introduction: The aim of the present study was to determine the susceptibility of lipids to Cu-induced peroxidation in diluted plasma and its relation with plasma lipids and lipoproteins in a group of healthy men.

Materials and Methods: In 100 healthy men volunteers (age range 20-55 years with a mean of $36.8 \pm 10.3$ years), fasting plasma levels of lipoprotein (a) [Lp (a)], total cholesterol (TC), high-density lipoprotein-cholesterol (HDL-C), low-density lipoprotein-cholesterol (LDL-C), and triglycerides (TG) were assayed. The Cu2+-induced lipid peroxidation was evaluated. Lipid oxidation was estimated by monitoring the change of conjugated dienes in the diluted plasma following the addition of $\mathrm{Cu}^{2+}$. The kinetic curves of the accumulation of lipid peroxide products were prepared, and a number of quantitative parameters including lag time, time of maximal oxidation rate (T-max), and maximal accumulation of absorbing products (OD-max) were evaluated.

Results: The TG concentrations were positively correlated with lag time and T-max $(r=0.33, P<0.01$ and $r=0.24, P<0.05)$ respectively. Also, TC and LDL-C were positively correlated with OD-max $(r=0.28, P<0.01$ and $r=0.26, P<0.05$ respectively), and HDL-C was negatively correlated $(\mathrm{r}=-0.23, P<0.05)$ with T-max. No significant correlation was observed between other variables and lipid oxidizability parameters.

Conclusions: Results of this research indicate that TG increased the resistance of LDL and VLDL against initiation of lipid oxidation. In addition, HDL-C induced the susceptibility of lipid oxidizability.

Keywords: Diluted Plasma, Copper, Lipid Oxidizability, Healthy Men

Citation: Jafari A, Jalali Khanabadi B, Nejadi N, Farhadihosseinabadi B. Association between plasma lipids profile and lipids oxidizability in healthy men. J Appl Biotechnol Rep. 2019;6(2):79-82. doi:10.29252/JABR.06.02.07.
\end{abstract}

\section{Introduction}

The oxidation of lipids and lipoproteins is involved in the pathogenesis of atherosclerosis. ${ }^{1}$ The modification of plasma lipoproteins, particularly low-density lipoproteins (LDLs), is responsible for the excessive internalization of oxidized LDL via the less tightly controlled scavenger receptor' pathway, which results in the formation of foam cells and atherosclerotic plaques. ${ }^{2}$ Lipoprotein(a) $[\mathrm{Lp}(\mathrm{a})]$ is one of the plasma lipoproteins that is considered as an independent risk factor for cardiovascular disease. ${ }^{3}$ It has been suggested that elevated levels of proinflammatory oxidized phospholipids primarily carried by LP(a) represents a genetic susceptibility to increased oxidative stress, which this claim is controversial. ${ }^{4,5}$ Much effort has been devoted to the development of in vitro assays for assessing the susceptibility of lipoproteins to various oxidants as well as to a possible correlation between the 'oxidizability' of LDL and lipid-related pathologies. ${ }^{6}$ Copperinduced oxidation of isolated LDL is frequently used as an in vitro model for the resistance of LDL lipids to oxidation. ${ }^{7,8}$ The lengthy procedure involved in LDL fractionation and the possible modification of the lipids during isolation of LDL, limit the clinical usefulness of kinetic data on LDL 'oxidizability' and justify further efforts aimed at the evaluation of the susceptibility of lipids to oxidation in no fractionated plasma or serum. ${ }^{9}$ Several studies have used plasma or serum as a biological model in this context. ${ }^{10,11}$ It seems that oxidation of lipids in the unfractionated plasma is a better, reliable, and flexible biological model to evaluate the lipid oxidizability. ${ }^{12-14}$ These studies have used whole serum or plasma diluted from 2 -fold to 150-fold and copper concentrations ranging from $50 \mathrm{mmol} / \mathrm{L}$ to $3.75 \mathrm{mmol} / \mathrm{L}$. ${ }^{12}$ Together, these studies have established that the measured oxidation in serum or plasma is a consequence of lipoprotein oxidation that correlates well with the oxidation of LDL. ${ }^{14-16}$ Copper-induced oxidation of lipids in non-fractionated serum is correlated with the complex nature of the interrelated effects of the various factors

Copyright $\odot 2019$ The Author(s). This is an open-access article distributed under the terms of the Creative Commons Attribution License (http:// creativecommons.org/licenses/by/4.0), which permits unrestricted use, distribution, and reproduction in any medium, provided the original work is properly cited. 
that influence the oxidation, including those of water-soluble antioxidants, anticoagulants used for plasma preparation and ions present in the diluting media. ${ }^{17,18}$ Considering that finding the best and most accurate method for measuring the oxidizability of LDL is still challenging, the present study has aimed to investigate the relationship between serum lipids level, especially LP (a), and lipid oxidizability. In the present study, serum plasma was used due to the lower cost in used method.

\section{Materials and Methods}

This descriptive and cross-sectional study was conducted on 100 randomized healthy men referred to Yazd Central Laboratory. The mean age was $36.8 \pm 10.3$ (ranged between 20 to 55 years). The inclusion criteria for enrolling the study included having a negative history for cardiovascular, hepatic, renal, genetic and endocrine disorders and also no positive history for smoking and hypertension. Blood samples were taken from the patients after 12 hours fasting and some were mixed with heparin for preparing plasma, and a part was incubated at room temperature for serum isolation for one hour.

In order to study lipid oxidizability, plasma was stored at $-70^{\circ} \mathrm{C}$ for a maximum 2 months period. The serum concentration of triglyceride and cholesterol were measured using "MAN". The high-density lipoprotein-cholesterol (HDL-C) was also determined by "Pars Azmoon" laboratory kits and TECHNICON-RA-1000 autoanalyzer.

Furthermore, LP (a) levels were measured by electro immunodiffusion techniques in the serum. Lipid oxidizability was studied by peroxidation products (Conjugated dynes) and the absorbance rate was measured at $245 \mathrm{~nm} .{ }^{12}$ Copperinduced plasma lipid peroxidation was estimated in 60 -fold diluted plasma in $20 \mathrm{mM} 60$ times by phosphate-buffered saline (PBS) containing $0.16 \mathrm{M} \mathrm{NaCl}$ and $720 \mu \mathrm{M}$ sodium citrate $(\mathrm{pH}=7.4)$. The lipid oxidation procedure was performed in a water bath at $37^{\circ} \mathrm{C}$ and initiated by adding $30 \mu \mathrm{L}$ of $4.5 \mathrm{mM}$ $\mathrm{CuSO}_{4}$ solution, to give final $\mathrm{Cu}^{2+}$ concentration of $70 \mu \mathrm{M}$. The kinetic of conjugated dienes formation was monitored by spectrophotometer (Dual wavelength spectrophotometer, Milton Ray) at $245 \mathrm{~nm}$, every 10 minutes for at least 300 minutes.

Excel Microsoft software program was used for plotting the kinetic curves of lipid peroxidation product (absorbance rate changes at $245 \mathrm{~nm}$ versus time in minute). A number of quantitative oxidation parameters including latency to onset of oxidation (Lag time), the maximum rate of oxidation (V-max), the maximum concentration of lipid peroxide products accumulation (OD max) and the time needed to gain the maximum rate of oxidation (T-max) were considered to evaluate the relationship between serum lipids level and lipid oxidizability.

\section{Statistical Analyses}

All quantitative data are presented as the mean \pm SD. Statistical analysis was performed using SPSS version 20. The student $t$ test, Pearson rank correlation coefficient were used to analyze the results according to the normal distribution of variables.

\section{Results}

The mean age of participants was $36.8 \pm 10.3$ years. Lipid levels and mean oxidizability parameters of plasma lipids are shown in Table 1 and Table 2, respectively. Mean of plasma Lp (a) level was $18.3 \pm 18.7 \mathrm{mg} / \mathrm{dL}$. When heparin plasma was diluted 60 -fold with PBS containing $0.15 \mathrm{M} \mathrm{NaCl}$ and incubated with $70 \mu \mathrm{M} \mathrm{Cu}{ }^{2+}$, its absorbance at $245 \mathrm{~nm}$ was found to increase (Figure 1). The oxidizability of the plasma was characterized using the parameters which are typically used to characterize the oxidizability of plasma, namely lag-phase and propagation phase duration and maximal oxidation rate (maximal oxidation rate measured within the propagation phase).

There was no significant correlation observed between serum Lp (a) levels and oxidizability parameters, but triglyceride concentration was significantly correlated with Lag time and $\operatorname{Tax}(P=0.001$ and $\mathrm{r}=0.33 ; P=0.01$ and $\mathrm{r}=0.28$, respectively). A negative, but not significant correlation was found between lag time and plasma cholesterol levels. The mean total cholesterol concentration was significantly

Table 1. Studied Variables in Population Study

\begin{tabular}{lc}
\hline Variables & Mean \pm SD \\
\hline Age & $36.8 \pm 10.3$ \\
Total cholesterol $(\mathrm{mg} / \mathrm{dL})$ & $200.9 \pm 40$ \\
Triglycerides $(\mathrm{mg} / \mathrm{dL})$ & $179.4 \pm 96.7$ \\
HDL-C $(\mathrm{mg} / \mathrm{dL})$ & $38 \pm 12.4$ \\
$\mathrm{LDL}-\mathrm{C}(\mathrm{mg} / \mathrm{dL})$ & $128.3 \pm 45.7$ \\
$\mathrm{LP}(\mathrm{a})(\mathrm{mg} / \mathrm{dL})$ & $18.3 \pm 18.7$ \\
\hline
\end{tabular}

Table 2. Mean of Quantitative Oxidation Parameters of Plasma Lipids

\begin{tabular}{lc}
\hline Variable & Mean \pm SD \\
\hline Lag Time $(\min )$ & $103.8 \pm 18.1$ \\
$T$ max $(\min )$ & $187.6 \pm 25.1$ \\
OD max & $0.508 \pm 0.123$ \\
$V$ max $(\mathrm{OD} / \mathrm{min})$ & $3.1 \pm 0.6$ \\
\hline
\end{tabular}

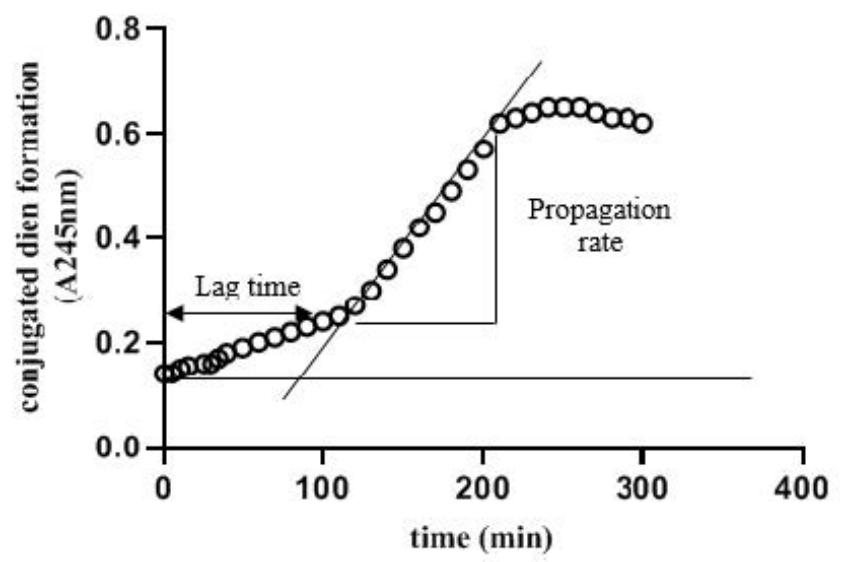

Figure 1. Conjugated Diene Monitoring During Copper-Induced Plasma Oxidation. Conjugated diene formation during copper-mediated plasma oxidation was monitored for $300 \mathrm{~min}$ by the changes in $245 \mathrm{~nm}$ wavelength absorbance. 
Table 3. Correlation Between Plasma Lipid and Lipoproteins Concentration and Quantitative Parameters of Oxidizability

\begin{tabular}{|c|c|c|c|c|c|}
\hline \multirow{2}{*}{ Variable } & \multicolumn{5}{|c|}{ Lipids } \\
\hline & LP(a) & HDL-C & LDL-C & Triglyceride & Total Cholesterol \\
\hline Lag-time (min) & $\mathrm{r}=-0.009, P=0.92$ & $r=-0.205, P=0.042$ & $\mathrm{r}=-0.06, P=0.56$ & $\mathrm{r}=0.337, P=0.001$ & $\mathrm{r}=0.006, P=0.95$ \\
\hline T-max & $r=-0.031, P=0.765$ & $r=-0.203, P=0.045$ & $\mathrm{r}=0.010, P=0.926$ & $\mathrm{r}=0.24, P=0.018$ & $\mathrm{r}=0.014, P=0.892$ \\
\hline OD-max & $r=-0.045, P=0.659$ & $r=-0.066, P=0.516$ & $\mathrm{r}=0.253, P=0.013$ & $\mathrm{r}=0.145, P=0.156$ & $\mathrm{r}=0.283, P=0.005$ \\
\hline
\end{tabular}

correlated with OD $\max (P=0.005, \mathrm{r}=0.28)$, while the mean plasma concentration of LDL-C was not correlated with $\mathrm{V}$ max and lag time, but there was a significant correlation with OD $\max (P=0.013, \mathrm{r}=0.25)$ (Table 3$)$.

\section{Discussion}

In this study, a significant relationship was found between the concentration of triglycerides levels with Lag time and $\mathrm{T}$ max, which was in accordance with the results from de Man et al's study. ${ }^{19}$ It seems that normal ranges of triglycerides, increases LDL resistance to oxidation in in vitro samples and alternatively, triglyceride-rich samples would be more resistant to oxidation. It is likely that the VLDL contains more antioxidants than LDL, and since the bulk of triglycerides are carried by VLDL, increasing the oxidation time will result in a triglycerides rise. As cholesterol is one of the oxidized substrates, increasing its concentration could be due to a rise in the maximum oxidation products. High cholesterol is also associated with increases in LDL/VLDL ration, which contain fewer antioxidants and is, therefore, more susceptible to oxidation. ${ }^{16}$ Another finding observed in this study was an inverse relationship between HDL concentration and the lag time, which indicates that HDL reduces resistance to oxidizability process. ${ }^{16,20}$ The most epidemiological studies indicate that plasma HDL is considered as a protective factor against coronary heart disease. The prevalence of atherosclerosis has been reported to be lower in the patients with high HDL levels. ${ }^{21}$ Actually, HDL can bind to cholesterol and lipid peroxidation products which inhibits LDL oxidation process. Moreover, HDL influences the release of endothelial relaxing factor and prostacyclin stability that plays a protective role against oxidation. ${ }^{22}$ On the contrary, the results from previous studies have shown that HDL ratio is more sensitive to oxidation induction process. ${ }^{23,24}$ Accordingly, HDL contains the main part of plasma lipid peroxides which is oxidized faster than LDL in vitro. Similar to oxidized LDL, oxidized HDL can convert to a toxic particle and start atherosclerosis. It is worth mentioning that HDL has beneficial properties such as stimulating the cholesterol flow from foam cells and antioxidant activity. These properties will be reduced following HDL oxidation. ${ }^{25}$ Besides, HDL oxidation and paraoxonase activity also lead to the loss of antioxidant activity. ${ }^{26}$ The HDL oxidation rate depends on several factors, such as HDL composition, particle size and concentration of the solution, which is used for oxidation as well as copper ion concentrations. ${ }^{27,28}$ As mentioned before, HDL is more susceptible to oxidation induction and also accelerates LDL oxidation progression. ${ }^{23}$ Hydroperoxides immigration from oxidized HDL to LDL (which is partially oxidized), followed by increased production of free radicals in LDL, is responsible for the LDL oxidation rise in the high concentrations of copper ion. ${ }^{29}$ In the present study, an inverse relation was detected between serum HDL and T max, which is in contrast to the findings of Lin et al. ${ }^{29}$ Also, LP(a) levels were not significantly associated with oxidizability parameters but a significant effect of LP(a) was not found on the oxidation rate and oxidizability, at least at low concentrations. ${ }^{30,31}$ Results may change if the oxidizability parameters get examined in subjects with high concentrations of Lp (a) (over $50 \mathrm{mg} / \mathrm{dL}$ ). Lipid and lipoprotein fractions (especially LDL) and total plasma can be used to study the oxidizability of lipoproteins and lipids. The main advantage of oxidizability examination on LDL is to remove the interference of other materials and components. It should be noted that LDL isolation is difficult and time-consuming and LDL damage would be likely to occur during the separation process. The disadvantage of oxidation induction on whole plasma is interfering components. Alternatively, this method is simpler and less expensive and does not require any special devices. Furthermore, this method gives a better image of oxidation conditions in vivo due to its biological environment. The major limitation of this study was that only male gender and healthy subjects were evaluated.

\section{Conclusions}

The results of this study showed that at least at low concentrations, serum Lp (a) has no significant effect on the rate of lipid oxidation and the lipids oxidizability properties in healthy subjects. Extremely LDLs and triglycerides show more resistance to oxidation compared to cholesterol and LDLs.

\section{Authors' Contributions}

BK designed the overall concept of the study. NN and AJ equally participated in the experiments. AJ analyzed data. BF and AJ equally contributed in writing, reviewing, and revising the manuscript.

Conflict of Interest Disclosures

No potential conflicts of interest were disclosed.

\section{Acknowledgments}

The authors thank the head of Yazd University of Medical Sciences, for approving and funding this project. They would also like to thank the Yazd Central Laboratory staff for collaborating in this study.

\section{References}

1. Koenig $\mathrm{W}$, Karakas $\mathrm{M}$, Zierer A, et al. Oxidized LDL and the risk of coronary heart disease: results from the MONICA/KORA Augsburg Study. Clin Chem. 2011;57(8):1196-1200. doi:10.1373/ 
clinchem.2011.165134.

2. Sharma M, Von Zychlinski-Kleffmann A, Porteous CM, Jones GT, Williams MJ, McCormick SP. Lipoprotein (a) upregulates ABCA1 in liver cells via scavenger receptor-B1 through its oxidized phospholipids. J Lipid Res. 2015;56(7):1318-1328. doi:10.1194/ jIr.M056150.

3. Kotani K, Yamada S, Yamada T, Taniguchi N, Sakurabayashi I. The relationship between oxidized lipoprotein(a) and carotid atherosclerosis in asymptomatic subjects: a comparison with native lipoprotein(a). Lipids Health Dis. 2011;10:174. doi:10.1186/1476511x-10-174.

4. Yeang C, Cotter B, Tsimikas S. Experimental animal models evaluating the causal role of lipoprotein (a) in atherosclerosis and aortic stenosis. Cardiovasc Drugs Ther. 2016;30(1):75-85. doi:10.1007/s10557-015-6634-1.

5. Niccoli G, Cin D, Scalone G, et al. Lipoprotein (a) is related to coronary atherosclerotic burden and a vulnerable plaque phenotype in angiographically obstructive coronary artery disease. Atherosclerosis. 2016;246:214-220. doi:10.1016/j. atherosclerosis.2016.01.020

6. Nagai M, Tani M, Kishimoto Y, et al. Sweet potato (Ipomoea batatas L.) leaves suppressed oxidation of low density lipoprotein (LDL) in vitro and in human subjects. J Clin Biochem Nutr. 2011;48(3):203208. doi:10.3164/jcbn.10-84.

7. Bayrak A, Bayrak T, Bodur E, Kilinc K, Demirpence E. The effect of HDL-bound and free PON1 on copper-induced LDL oxidation. Chem Biol Interact. 2016;257:141-146. doi:10.1016/j. cbi.2016.08.007.

8. Lee KW, Choo WD, Kang CW, An BK. Effect of lycopene on the copper-induced oxidation of low-density lipoprotein in broiler chickens. Springerplus. 2016;5:389. doi:10.1186/s40064-0162035-6.

9. Miljkovic M, Stefanovic A, Simic-Ogrizovic S, et al. Association of dyslipidemia, oxidative stress, and inflammation with redox status in VLDL, LDL, and HDL lipoproteins in patients with renal disease. Angiology. 2018;69(10):861-870. doi:10.1177/0003319718780041.

10. Swertfeger DK, Rebholz S, Li H, Shah AS, Davidson WS, Lu LJ. Feasibility of a plasma bioassay to assess oxidative protection of low-density lipoproteins by high-density lipoproteins. J Clin Lipidol. 2018;12(6):1539-1548. doi:10.1016/j.jacl.2018.08.007.

11. Pereira CD, Minamino N, Takao T. Free thiol of transthyretin in human plasma most accessible to modification/oxidation. Anal Chem. 2015;87(21):10785-10791. doi:10.1021/acs. analchem.5b03431.

12. Schnitzer E, Pinchuk I, Bor A, Fainaru M, Samuni AM, Lichtenberg D. Lipid oxidation in unfractionated serum and plasma. Chem Phys Lipids. 1998;92(2):151-170. doi:10.1016/S0009-3084(98)000218.

13. Mehdi MM, Rizvi Sl. Human plasma paraoxonase 1 (PON1) arylesterase activity during aging: correlation with susceptibility of LDL oxidation. Arch Med Res. 2012;43(6):438-443. doi:10.1016/j. arcmed.2012.08.012.

14. Pinchuk I, Shoval H, Bor A, Schnitzer E, Dotan Y, Lichtenberg D. Ranking antioxidants based on their effect on human serum lipids peroxidation. Chem Phys Lipids. 2011;164(1):42-48. doi:10.1016/j.chemphyslip.2010.10.002.

15. Calzada C, Colas R, Guillot N, et al. Subgram daily supplementation with docosahexaenoic acid protects low-density lipoproteins from oxidation in healthy men. Atherosclerosis. 2010;208(2):467-472. doi:10.1016/j.atherosclerosis.2009.07.049.

16. Ide T, Origuchi I. Physiological effects of an oil rich in gammalinolenic acid on hepatic fatty acid oxidation and serum lipid levels in genetically hyperlipidemic mice. J Clin Biochem Nutr. 2019;64(2):148-157. doi:10.3164/jcbn.18-64.

17. Baldi S, Innocenti $M$, Frascerra $S$, et al. Effects of hemodialysis and vitamin $\mathrm{E}$ supplementation on low-density lipoprotein oxidizability in end-stage renal failure. J Nephrol. 2013;26(3):549555. doi:10.5301/jn.5000190.

18. lughetti L, Perugini C, Predieri B, et al. Low-density lipoprotein oxidizability in children with chronic renal failure. Pediatr Int. 2008;50(4):447-453. doi:10.1111/j.1442-200X.2008.02614.x.

19. de Man FH, Jonkers IJ, Schwedhelm E, et al. Normal oxidative stress and enhanced lipoprotein resistance to in vitro oxidation in hypertriglyceridemia: effects of bezafibrate therapy. Arterioscler Thromb Vasc Biol. 2000;20(11):2434-2440. doi:10.1161/01. ATV.20.11.2434.

20. Cohen E, Aviram M, Khatib S, Volkova N, Vaya J. Human carotid atherosclerotic plaque protein(s) change HDL protein(s) composition and impair HDL anti-oxidant activity. Biofactors. 2016;42(1):115-128. doi:10.1002/biof.1254.

21. Rosenson RS, Brewer HB Jr, Ansell BJ, et al. Dysfunctional HDL and atherosclerotic cardiovascular disease. Nat Rev Cardiol. 2016;13(1):48-60. doi:10.1038/nrcardio.2015.124.

22. Annema $\mathrm{W}$, Willemsen $\mathrm{HM}$, de Boer JF, et al. HDL function is impaired in acute myocardial infarction independent of plasma HDL cholesterol levels. J Clin Lipidol. 2016;10(6):1318-1328. doi:10.1016/j.jacl.2016.08.003.

23. Solakivi T, Jaakkola O, Salomaki A, et al. HDL enhances oxidation of LDL in vitro in both men and women. Lipids Health Dis. 2005;4:25. doi:10.1186/1476-511x-4-25.

24. Yamazaki D, Ishida M, Nobori K, et al. Comparison of Inflammatory Markers and Lipid Profile Between High-dose Rosuvastatin Monotherapy and Ezetimibe/Rosuvastatin Combination Therapy. J Card Fail. 2012;18(10):S163. doi:10.1016/j.cardfail.2012.08.202.

25. Ormseth MJ, Stein CM. High-density lipoprotein function in rheumatoid arthritis. Curr Opin Lipidol. 2016;27(1):67-75. doi:10.1097/mol.0000000000000256.

26. Unal E, Eris C, Kaya B, et al. Paraoxonase and arylesterase activities, lipid profile, and oxidative damage in experimental ischemic colitis model. Gastroenterol Res Pract. 2012;2012:979506. doi:10.1155/2012/979506.

27. Shuhei N, Soderlund S, Jauhiainen M, Taskinen MR. Effect of $\mathrm{HDL}$ composition and particle size on the resistance of HDL to the oxidation. Lipids Health Dis. 2010;9:104. doi:10.1186/1476511X-9-104.

28. Yang Y, Yan B, Fu M, Xu Y, Tian Y. Relationship between plasma lipid concentrations and HDL subclasses. Clin Chim Acta. 2005;354(12):49-58.doi:10.1016/j.cccn.2004.11.015.

29. Lin KY, Chen YL, Shih CC, Pan JP, Chan WE, Chiang AN. Contribution of HDL-apolipoproteins to the inhibition of low density lipoprotein oxidation and lipid accumulation in macrophages. J Cell Biochem. 2002;86(2):258-267.doi:10.1002/jcb.10210.

30. Galvano F, Malaguarnera M, Vacante M, et al. The physiopathology of lipoprotein (a). Front Biosci (Schol Ed). 2010;2(3):866-875. doi:10.2741/S107.

31. Lamon-Fava S, Marcovina SM, Albers JJ, et al. Lipoprotein(a) levels, apo(a) isoform size, and coronary heart disease risk in the Framingham Offspring Study. J Lipid Res. 2011;52(6):1181-1187. doi:10.1194/jlr.M012526. 